\title{
Characterisation of beta-cell dysfunction of impaired glucose tolerance: Evidence for impairment of incretin-induced insulin secretion
}

\author{
A. Fritsche, N.Stefan, E. Hardt, H.Häring, M.Stumvoll \\ Medical Clinic, Department of Endocrinology, Metabolism and Pathobiochemistry, University of Tübingen, Germany
}

\begin{abstract}
Aims/hypothesis. Our studies were undertaken to characterise the defective insulin secretion of impaired glucose tolerance (IGT).

Methods. We studied 13 normal glucose tolerant subjects (NGT) and 12 subjects with IGT carefully matched for age, sex, BMI and waist-to-hip ratio. A modified hyperglycaemic clamp $(10 \mathrm{mmol} / \mathrm{l})$ with a standard 2-h square-wave hyperglycaemia, an additional glucagon-like-peptide (GLP)-1 phase (1.5 $\mathrm{pmol} \cdot \mathrm{kg}^{-1} \cdot \mathrm{min}^{-1}$ over $\left.80 \mathrm{~min}\right)$ and a final arginine bolus $(5 \mathrm{~g})$ was used to assess various phases of insulin secretion rate.

Results. Insulin sensitivity during the second phase of the hyperglycaemic clamp was low in both groups but not significantly different $(0.12 \pm 0.021$ in NGT vs $0.11 \pm 0.013 \mu \mathrm{mol} \cdot \mathrm{kg}^{-1} \cdot \mathrm{min}^{-1} \cdot \mathrm{pmol}^{-1}$ in IGT, $p=$ $0.61)$. First-phase insulin secretion was lower in IGT $\left(1467 \pm 252\right.$ vs $\left.3198 \pm 527 \mathrm{pmol} \cdot \mathrm{min}^{-1}, p=0.008\right)$ whereas the second phase was not $(677 \pm 61$ vs $\left.878 \pm 117 \mathrm{pmol} \cdot \min ^{-1}, p=0.15\right)$. The acute insulin
\end{abstract}

secretory peak in response to GLP-1 was absent in IGT subjects who only produced a late phase of GLP-1-induced insulin secretion rate which was lower $\left(2228 \pm 188 \mathrm{pmol} \cdot \mathrm{min}^{-1}\right)$ than in NGT subjects $\left(3056 \pm 327 \mathrm{pmol} \cdot \mathrm{min}^{-1}, p=0.043\right)$. Insulin secretion in response to arginine was considerably although not significantly lower in IGT subjects. The relative impairment (per cent of the mean rate for NGT subjects) was greatest for the GLP-1 peak (19 $\pm 9 \%)$.

Conclusion/interpretation. In this Caucasian cohort a defective insulin secretion rate is essential for the development of IGT. The variable degrees of impairment of different phases of the insulin secretion rate indicate that several defects contribute to its abnormality in IGT. Defects in the incretin signalling pathway of the beta cell could contribute to the pathogenesis of beta-cell dysfunction of IGT and thus Type II (non-insulin-dependent) diabetes mellitus. [Diabetologia (2000) 43: 852-858]

Keywords Type II diabetes, insulin resistance, GLP-1, arginine.
The pathogenesis of Type II (non-insulin-dependent) diabetes mellitus involves a combination of impaired insulin secretion and insulin resistance [1]. Because

Received: 13 December 1999 and in revised form: 21 February 2000

Corresponding author: Dr M. Stumvoll, Medizinische Universitätsklinik, Otfried-Müller-Str. 10, D-72076 Tübingen, Germany

Abbreviations: GLP-1, Glucagon-like peptide-1; ISR, insulin secretion rate; AIR, acute insulin secretory response to arginine; GLP AIR, acute insulin secretory response to GLP-1. both could be secondary to so-called "glucose toxicity" [2] or environmental factors such as obesity, fat distribution or diet [3], it is still controversial which of these factors represents the underlying defect. One approach to narrow down the possible sites of the defect is to clinically characterise the abnormality in people who are likely to carry the genetic defect(s) but are not yet overtly hyperglycaemic. Thus, an ideal study group includes first-degree relatives of patients with Type II diabetes (prediabetic) and subjects with mildly impaired glucose tolerance (IGT). Whereas only 40\% [4] of the former group progress to manifest diabetes, the clinical penetrance 
of any underlying defect in people with IGT approaches $100 \%$ [5].

Earlier studies suggested that insulin resistance is the main defect responsible for the development of IGT [6-8]. These studies did not, however, adequately control for environmental factors, in particular obesity $[6,8]$ or were done in a specific ethnic group [7]. In contrast, a number of recent studies have indicated that people with IGT have impaired insulin secretion [9-11]. In these studies glucose was exclusively used as the insulin secretagogue. An oral glucose load given to assess glucose tolerance, however, stimulates insulin secretion not only through glucose but also through incretins [12] and possibly other secretagogues.

The incretin glucagon-like peptide-1 (GLP-1) for instance, has been shown to greatly enhance insulin secretion in the presence of hyperglycaemia [13, 14]. In contrast, arginine-induced insulin secretion which involves multiple cellular mechanisms (nitric oxide, glucagon, amino-acid transport) $[15,16]$ seems to be partially independent of hyperglycaemia [17]. The impaired insulin secretion observed in IGT most likely represents the net effect of several distinct, possibly genetically determined, abnormalities of the beta cell. Thus, use of different secretagogues should allow the assessment of specific aspects of the insulin secretory defect of IGT.

Therefore, we studied various aspects of beta-cell function and insulin sensitivity in 12 subjects with IGT and 13 normal glucose tolerant control subjects carefully matched for age, sex, BMI, waist-to-hip ratio and $\mathrm{HbA}_{1 \mathrm{c}}$. For this purpose we used a modified hyperglycaemic clamp $(10 \mathrm{mmol} / \mathrm{l})$ in which the standard 2-h square-wave hyperglycaemia was followed by additional treatment with GLP-1 over $80 \mathrm{~min}$ and a final arginine bolus. Insulin sensitivity was determined during the second phase of the hyperglycaemic clamp. The specific aim of the study was to determine the relative impairment of insulin secretion in response to different secretagogues in IGT.

\section{Subjects and methods}

Subjects. We studied 13 healthy, normal glucose tolerant volunteers and 12 subjects with impaired glucose tolerance (IGT) all of German origin. The characteristics of the subjects are shown in Table 1 . The family histories of the subjects were not suggestive of maturity-onset diabetes of the young (MODY) diabetes. They did not take any medication known to affect glucose tolerance, insulin sensitivity or insulin secretion. A 75-g oral glucose tolerance test was done to classify subjects according to World Health Organisation (WHO) criteria [18].

Clamp protocols. The study protocol was approved by the ethics committee of the University of Tübingen. Before the study, informed written consent was obtained from all participants. All subjects underwent a modified hyperglycaemic clamp
Table 1. Demographics of subjects with normal glucose tolerance (NGT) and impaired glucose tolerance (IGT)

\begin{tabular}{llll}
\hline & NGT & IGT & $p$ value \\
\hline$n$ (men/women) & $7 / 6$ & $7 / 5$ & \\
Age (years) & $42.7 \pm 3.6$ & $43.8 \pm 4.9$ & 0.85 \\
Body weight (kg) & $81.0 \pm 3.0$ & $77.3 \pm 2.5$ & 0.36 \\
BMI (kg/m $\left.{ }^{2}\right)$ & $27.0 \pm 0.8$ & $26.1 \pm 0.8$ & 0.45 \\
Waist-to-hip ratio & $0.90 \pm 0.02$ & $0.88 \pm 0.02$ & 0.55 \\
Fasting plasma glucose (mmol/l) & $5.01 \pm 0.18$ & $5.66 \pm 0.23$ & 0.03 \\
HbA $_{1 \mathrm{c}}(\%)$ & $5.3 \pm 0.1$ & $5.5 \pm 0.1$ & 0.29 \\
Fasting plasma insulin (pmol/l) & $63 \pm 12$ & $70 \pm 12$ & 0.72 \\
\hline
\end{tabular}

(10 mmol/l) and were given GLP-1 and arginine. Subjects had been instructed to maintain their usual diet before the study. After an overnight fast, at around 0800 hours a dorsal hand vein was cannulated retrogradely and kept in a thermoregulated box at $55^{\circ} \mathrm{C}$ to obtain arterialised blood samples. At the same time, an antecubital vein of the contralateral arm was cannulated for infusions. After baseline samples had been obtained, a hyperglycaemic clamp was carried out as described previously [19]. An intravenous bolus of $20 \%$ glucose over $1 \mathrm{~min}$ was given to instantaneously raise blood glucose to $10 \mathrm{mmol} / \mathrm{l}$ [bolus dose $(\mathrm{mg})=$ body weight $(\mathrm{kg}) \times$ desired increase in blood glucose $(\mathrm{mmol} / \mathrm{l}) \cdot 27]$. Subsequently, a glucose infusion was adjusted to maintain blood glucose at $10 \mathrm{mmol} / \mathrm{l}$. After 120 min GLP-1 [human GLP-1 (7-36) amide, (Poly Peptide, Wolfenbüttel, Germany)] was given as a primed and continuous infusion $\left(0.6 \mathrm{pmol} / \mathrm{kg} ; 1.5 \mathrm{pmol} \cdot \mathrm{kg}^{-1} \cdot \mathrm{min}^{-1}\right)$ during the next $80 \mathrm{~min}$ [20]. At $180 \mathrm{~min}$ a bolus of $5 \mathrm{~g}$ arginine hydrochloride (Pharmacia, Erlangen, Germany) was injected over $45 \mathrm{~s}$ while the GLP-1 infusion was continued. In all subjects GLP-1 was used from the same batch.

Plasma glucose was determined bedside with a HemoCue blood glucose photometer (HemoCue, Aengelholm, Sweden) at 5 min intervals. Samples for insulin (Microparticle Enzyme Immunoassay, Abbott Laboratories, Tokyo, Japan, CV 2.5-6\%) and C-peptide (RIA, Byk-Sangtec, Dietzenbach, Germany) measurement were taken at $-30,-15,0,2.5,5,7.5$, $10,20,40,60,80,100,120,125,130,140,150,160,170,180$, $182.5,185,187.5,190$ and $200 \mathrm{~min}$.

Measurement of insulin secretion rate (ISR). Standard kinetic parameters for $\mathrm{C}$ peptide (rate constants, volume of distribution) adjusted for age, sex, BMI and body surface area were used [21] and assumed to remain unchanged throughout the experiment. These parameters were used to calculate the ISR for the time intervals indicated above from the plasma C-peptide concentrations by deconvolution as described previously [22].

Phases of insulin secretion and insulin sensitivity. The calculation of the individual phases of insulin secretion have been standardised (Table 2). An acute response of insulin secretion rate has been defined as the response within $10 \mathrm{~min}$ to a stimulus (glucose, GLP-1 or arginine). This response has to form a clearly discernible peak. Insulin sensitivity was assessed as an insulin sensitivity index, calculated by dividing the average glucose infusion rate during the last $40 \mathrm{~min}$ of the hyperglycaemic clamp by the average plasma insulin concentration during the same interval [19]. For the purpose of graphical display mean glucose infusion rates were calculated for 5-min intervals during acute phases, otherwise for 10-min intervals.

Statistical analysis. Data are given as means \pm SEM. Comparisons between NGT and IGT subjects for specific time points 
Table 2. Calculations of different phases of insulin secretion

\begin{tabular}{lll}
\hline Description of variable & Denotation used & ISR, time points used for calculation of phase \\
\hline First-phase glucose-stimulated insulin secretion & First phase & Sum of 2.5 and 5 min \\
Second-phase glucose-stimulated insulin secretion & Second phase & Mean of $(80+100+120 \mathrm{~min})$ \\
Acute insulin secretory response to GLP-1 & GLP AIR & 125 min minus mean of $(80+100+120 \mathrm{~min})$ \\
Peak of GLP-1-induced insulin secretion & GLP peak & 125 min minus mean of $(160+150+180$ min $)$ \\
Plateau of GLP-1-induced insulin secretion & GLP plateau & Mean of $(160+170+180$ min $)$ \\
Maximum insulin secretion & Maximum & 182.5 min \\
Acute insulin secretory response to arginine & AIR & 182.5 minus 180 min \\
\hline
\end{tabular}
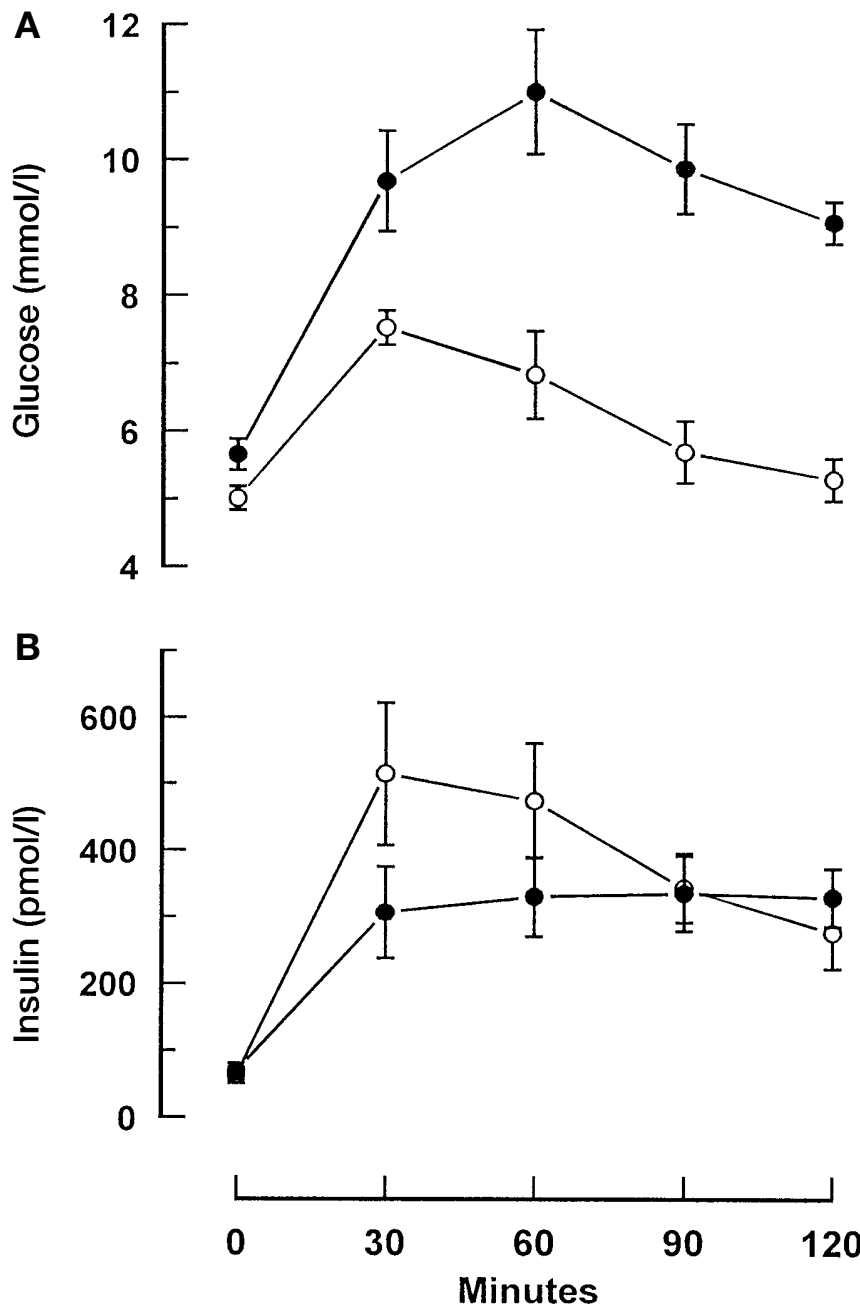

Fig.1A, B. Blood glucose (A) and serum insulin (B) in subjects $(n=13)$ with normal glucose tolerance $(\bigcirc)$ and subjects $(n=12)$ with impaired glucose tolerance $(\mathcal{O})$ during a $75-\mathrm{g}$ oral glucose tolerance test

were made using an unpaired Student's $t$ test (two-tailed). A $p$ value of less than 0.05 was considered statistically significant. The relative impairment of insulin secretion in IGT was assessed by expressing each phase as a percentage of the mean value in NGT subjects. For multiple comparisons we did an analysis of variance with Duncan's procedure for multiple range tests (alpha level 0.05). The software package SPSS/ PC + (SPSS, Chicago, Ill., USA) was used for statistical analysis.

\section{Results}

Oral glucose tolerance test (Fig. 1). The glucose and insulin curves during the oral glucose tolerance test were clearly different between IGT and NGT subjects (Fig.1). The blood glucose concentration in IGT subjects was higher at all time points and the area under the glucose curve was $227 \pm 12 \mathrm{mmol} \cdot \mathrm{l}^{-1} \cdot \mathrm{h}^{-1}$ in NGT vs $341 \pm 21 \mathrm{mmol} \cdot \mathrm{l}^{-1} \cdot \mathrm{h}^{-1}$ in IGT subjects $(p<0.001)$. The area under the insulin curve was not significantly different between NGT $\left(752 \pm 115 \mathrm{pmol} \cdot \mathrm{l}^{-1} \cdot \mathrm{h}^{-1}\right)$ and IGT subjects $\left(586 \pm 95 \mathrm{mmol} \cdot \mathrm{l}^{-1} \cdot \mathrm{h}^{-1}, p=0.3\right)$.

Plasma insulin concentrations during the modified hyperglycaemic clamp (Fig. 2). During the first phase of the hyperglycaemic clamp insulin concentrations increased from $50 \pm 8 \mathrm{pmol} / \mathrm{l}$ at baseline to a peak value of $375 \pm 81 \mathrm{pmol} / \mathrm{l}$ in NGT and from $48 \pm 4 \mathrm{pmol} / \mathrm{l}$ at baseline to a peak value of $162 \pm 26 \mathrm{pmol} / \mathrm{l}$ in IGT subjects $(p=0.02)$. After reaching a trough at about $20 \mathrm{~min}$ insulin increased progressively to $458 \pm 120 \mathrm{pmol} / \mathrm{l}$ in NGT and to $229 \pm 28 \mathrm{pmol} / \mathrm{l}$ in IGT subjects $(p=0.08)$ at $120 \mathrm{~min}$. In response to the GLP-1 priming-dose insulin concentrations rose sharply to $1981 \pm 340 \mathrm{pmol} / \mathrm{l}$ at $125 \mathrm{~min}$ in NGT and to $716 \pm 83 \mathrm{pmol} / \mathrm{l}$ in IGT subjects $(p=0.001)$. Subsequently insulin increased progressively to $5866 \pm 1000 \mathrm{pmol} / \mathrm{l}$ in NGT and $2098 \pm 322 \mathrm{pmol} / \mathrm{l}$ in IGT subjects $(p=0.002)$ at $180 \mathrm{~min}$. In response to the arginine bolus, insulin concentrations once again rose to a peak value of $8988 \pm 1260 \mathrm{pmol} / \mathrm{l}$ in NGT and $4035 \pm 346 \mathrm{pmol} / \mathrm{l}$ in IGT subjects $(p=0.001)$ at $182.5 \mathrm{~min}$.

Insulin secretion rates (ISR) during the modified hyperglycaemic clamp (Fig. 2). During the first phase of the hyperglycaemic clamp the mean ISR (measured from the C-peptide concentrations) increased from $178 \pm 22 \mathrm{pmol} \cdot \mathrm{min}^{-1}$ at baseline to a peak of $2367 \pm 443 \mathrm{pmol} \cdot \mathrm{min}^{-1}$ in NGT and from $206 \pm 15$ $\mathrm{pmol} \cdot \mathrm{min}^{-1}$ at baseline to a peak of $810 \pm 212$ $\mathrm{pmol} \cdot \mathrm{min}^{-1}$ in IGT subjects $(p=0.005)$. After reaching a trough at about $20 \mathrm{~min}$ the mean ISR increased progressively to $892 \pm 115 \mathrm{pmol} \cdot \mathrm{min}^{-1}$ in NGT and to $672 \pm 56 \mathrm{pmol} \cdot \mathrm{min}^{-1}$ in IGT subjects $(p=0.11)$ at $120 \mathrm{~min}$. In response to the GLP-1 priming-dose the mean ISR rose to a sharp peak of $5429 \pm 820$ 


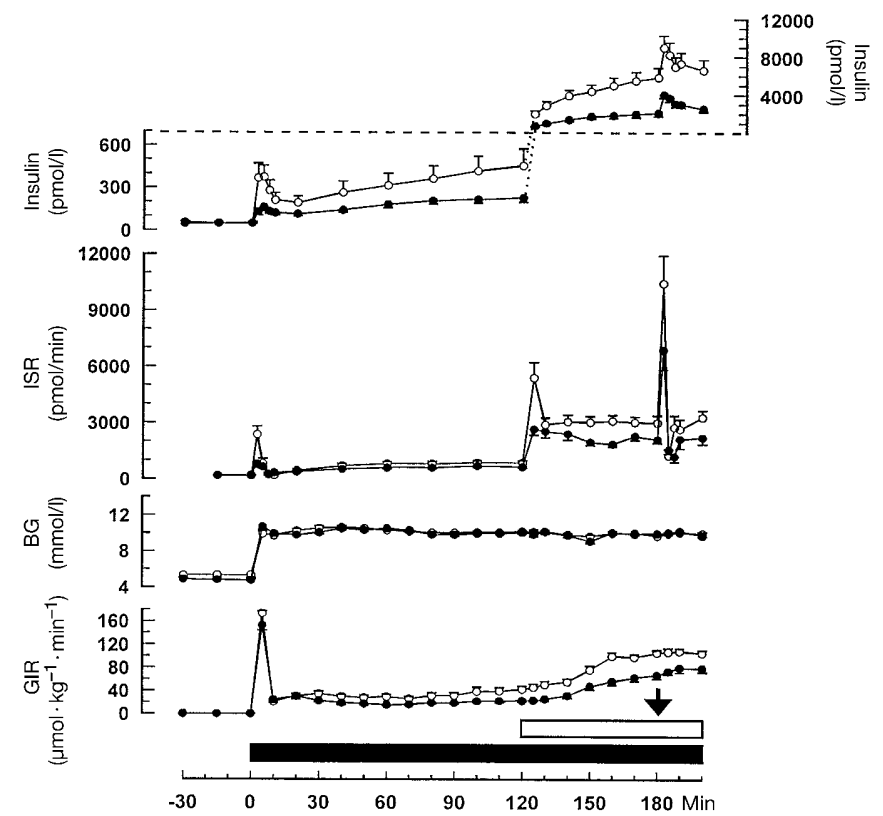

Fig. 2. Glucose infusion rates (GIR), blood glucose concentration (BG), insulin secretion rates (calculated from plasma $\mathrm{C}$ peptide concentrations by deconvolution) and plasma concentrations of insulin at baseline and during $200 \mathrm{~min}$ of the hyperglycaemic clamp in NGT $(\bigcirc)$ and IGT $(O)$ subjects. Note that for clarity reasons the y-axis for insulin was split and continued on the right with a different scale. Arrow denotes arginine $(5 \mathrm{~g})$ bolus, open bar denotes GLP-1 infusion $(0.6 \mathrm{pmol} / \mathrm{kg}$; $1.5 \mathrm{pmol} / \mathrm{kg} \cdot \mathrm{min})$, solid bar denotes hyperglycaemia (10 mmol/l)

Table 3. Comparison of different phases of insulin secretion between subjects with NGT and IGT

\begin{tabular}{lccl}
\hline & NGT & IGT & $p$ value \\
\hline First phase & $3198 \pm 527$ & $1467 \pm 252$ & 0.008 \\
Second phase & $878 \pm 117$ & $677 \pm 61$ & 0.15 \\
GLP AIR & $5041 \pm 777$ & $2098 \pm 277$ & 0.007 \\
GLP peak & $2373 \pm 636$ & $452 \pm 223$ & 0.01 \\
GLP plateau & $3056 \pm 327$ & $2228 \pm 188$ & 0.043 \\
Max & $10476 \pm 1479$ & $6916 \pm 1044$ & 0.065 \\
AIR & $7430 \pm 1281$ & $4783 \pm 961$ & 0.12 \\
\hline
\end{tabular}

Means \pm SEM; insulin secretion rates are given in $\mathrm{pmol} / \mathrm{min}$. Max $=$ maximum insulin secretion

$\mathrm{pmol} \cdot \mathrm{min}^{-1}$ at $125 \mathrm{~min}$ in NGT but only to $2681 \pm$ $312 \mathrm{pmol} \cdot \mathrm{min}^{-1}$ in IGT subjects $(p=0.006)$ without forming a similar peak. Subsequently, the mean ISR levelled off at $3046 \pm 381 \mathrm{pmol} \cdot \mathrm{min}^{-1}$ in NGT and $2133 \pm 169 \mathrm{pmol} \cdot \mathrm{min}^{-1}$ in IGT subjects by $180 \mathrm{~min}$ $(p=0.04)$. In response to the arginine bolus the ISR again rose to a peak value of $10476 \pm 1479$ pmol . $\mathrm{min}^{-1}$ in NGT and $6916 \pm 1044 \mathrm{pmol} \cdot \mathrm{min}^{-1}$ in IGT subjects $(p=0.07)$ at $182.5 \mathrm{~min}$. With the exception of the second phase $(p=0.15)$ and acute insulin secretory response to arginine (AIR) $(p=0.12)$ all phases of insulin secretion were significantly higher in NGT than in IGT subjects (Table 3).

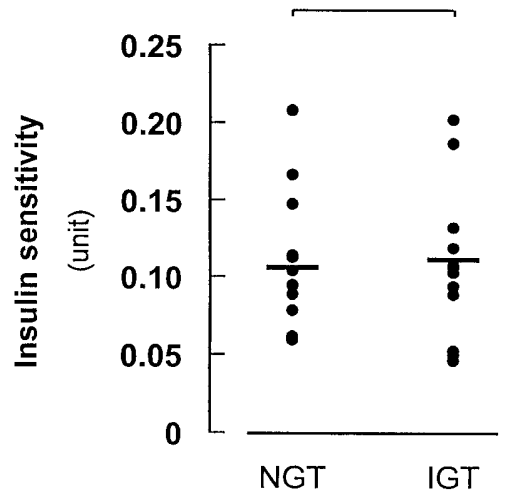

Fig.3. Insulin sensitivity determined during the second phase of hyperglycaemia in NGT and IGT subjects. The bracket denotes statistical comparison between NGT and IGT $(p=0.61)$

Insulin sensitivity (Fig. 3). The glucose infusion rate necessary to maintain a blood glucose concentration of $10 \mathrm{mmol} / \mathrm{l}$ between 80 and $120 \mathrm{~min}$ was $37 \pm 6 \mu \mathrm{mol} \cdot \mathrm{kg}^{-1} \cdot \mathrm{min}^{-1}$ in NGT and $21 \pm 2 \mu \mathrm{mol}$. $\mathrm{kg}^{-1} \cdot \min ^{-1}$ in IGT subjects $(p=0.019)$. The insulin sensitivity index as determined by relating this glucose infusion rate to the mean insulin concentrations during the same interval was not significantly different between NGT $\left(0.12 \pm 0.02 \mu \mathrm{mol} \cdot \mathrm{kg}^{-1} \cdot \mathrm{min}^{-1}\right.$. $\left.\mathrm{pmol} \cdot \mathrm{l}^{-1}\right)$ and IGT subjects $\left(0.11 \pm 0.01 \mu \mathrm{mol} \cdot \mathrm{kg}^{-1}\right.$. $\left.\min ^{-1} \cdot \mathrm{pmol} \cdot 1^{-1}, p=0.61\right)$.

Relative impairment of insulin secretion in response to different secretagogues in subjects with impaired glucose tolerance (Fig. 4). Insulin secretion in the subjects with IGT expressed as the per cent of the mean insulin secretion rates in subjects with NGT clearly differed between the individual phases of insulin secretion. The relative impairment of insulin secretion was greatest for the acute GLP phase (GLP-peak) $(19 \pm 9 \%$ of the mean NGT value) which was lower than for the first phase $(40 \pm 7 \%$ of the mean NGT value, $p=0.04)$. The insulin secretion peak in the NGT group in response to GLP-1 was absent in the IGT group (Fig. 2). In contrast, in the second phase of hyperglycaemia, the GLP-plateau $(73 \pm 6 \%$ of the mean NGT value) and the acute insulin response to arginine $(66 \pm 10 \%$ of the mean NGT value) were relatively least impaired.

\section{Discussion}

In the subjects with IGT most phases of insulin secretion were significantly reduced compared with the control group. The insulin sensitivity was not significantly different between the two groups. It is important to point out that the matching process in this study excluded the effect of obesity, body fat distribution, age and sex which are associated with insulin resistance [3]. Thus, our data clearly show that for a giv- 


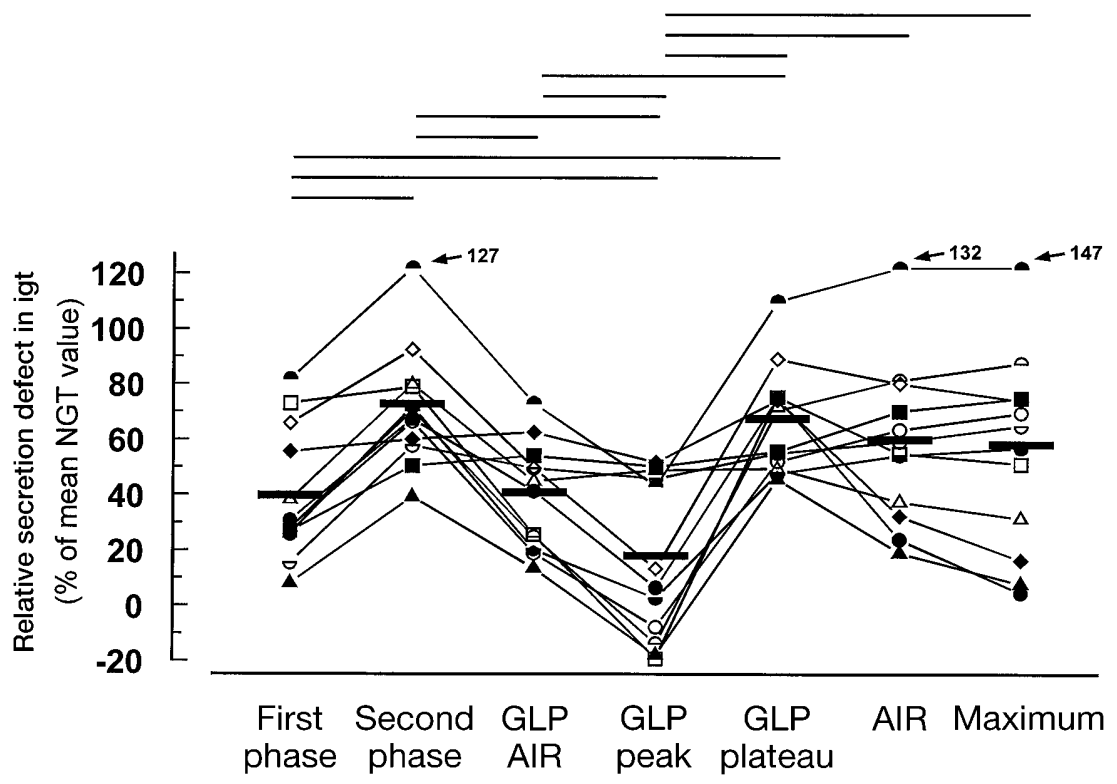

Fig.4. Relative impairment of insulin secretion in response to different secretagogues in subjects with impaired glucose tolerance. Data are expressed as the per cent of insulin secretion in subjects with normal glucose tolerance. Horizontal lines denote statistical difference $(p<0.05)$ using Duncan's procedure for multiple comparisons

en degree of insulin resistance an additional defect in insulin secretion is necessary to produce impaired glucose tolerance. This is consistent with a previous study finding no difference for insulin sensitivity in analogously matched groups using the hyperinsulinaemic euglycaemic clamp technique although insulin secretion determined by the hyperglycaemic clamp was significantly lower [9].

In addition to simply quantifying insulin secretion as such we made an effort to elaborate different qualities of beta-cell dysfunction. The IGT group did not behave homogeneously in the relative impairment of the different phases. Displaying the individual data shows that the pattern of impairment varies greatly between subjects. For example, one subject $(\diamond)$ reached $55 \%$ of the normal first phase but not even $20 \%$ of the average maximum secretion. Another subject $(\bigcirc)$ produced an almost normal maximum secretion but the GLP peak was entirely absent.

A surprising finding of the study was the presence of a sharp peak in insulin secretion in response to the start of the GLP infusion in the NGT subjects. This finding might represent a new variable of betacell function. In the subjects with IGT in contrast, this initial peak response was absent and could represent a characteristic of subjects with IGT. A reduced incretin effect on insulin secretion was previously shown in patients with overt Type II diabetes [23]. In that study long-standing hyperglycaemia could, however, have resulted in a secondary secretion defect non-specific for a particular secretagogue. In contrast in our study we could show a defective GLP-1 effect before the onset of overt hyperglycaemia.

The failure of the IGT subjects to produce an acute secretory phase in response to the GLP-1-priming dose (calculated on a body-weight basis) contrasts with the clearly discernible, albeit small, first phase in response to the glucose prime and the almost normal response to arginine. This suggests that a betacell defect specifically in the GLP-1-dependent signalling pathway could be involved in the pathogenesis of the secretory failure of IGT and thus Type II diabetes. Although such a molecular defect could theoretically exist independently of other defects, e.g. in glucose-induced insulin secretion itself, it is more likely that a combination is necessary for the manifestation of defective insulin secretion. That the GLP-1 peak was significantly more reduced than the firstphase peak in response to glucose $(80 \%$ vs $60 \%$ for first phase) could indicate that loss of the former is a very sensitive sign of early beta-cell failure, at least in some subjects.

It is necessary to point out that our arbitrary definition of the GLP-1 peak, i.e. peak value minus late plateau of GLP-1, somewhat overemphasises the loss of the acute insulin secretory response to GLP1. The acute rise above the prestimulus concentration (GLP AIR) in contrast, was defective to a similar proportion as the first phase. It could also be argued that GLP-1 as a secretagogue simply magnifies any defect in glucose-stimulated insulin secretion. The NGT subjects clearly produced, however, a true peak of insulin secretion in response to the GLP-1 prime whereas in the IGT group insulin secretion increased only in a square-wave fashion. In our view, this primarily qualitative difference is most appropriately quantified by expressing the peak as the maximum value minus the later plateau. Moreover, the observa- 
tion that the GLP plateau was significantly lower in IGT but the second phase of hyperglycaemia was not, might support the idea of a specific defect in the incretin pathway being involved at least in some subjects (e.g. $\Delta$ in Fig. 4 ).

Our data are somewhat at variance with the observation that the GLP-1 effect on insulin secretion was only marginally lower in patients with Type II diabetes than in normal control subjects [13]. Differences in subjects (younger age, no pretreatment with sulphonylureas) and experimental design (preceding 2$\mathrm{h}$ hyperglycaemia, higher glucose concentration during the clamp) could explain the apparent discrepancy to some extent. We are, however, unable to fully explain why in subjects with Type II diabetes in whom greater beta-cell dysfunction would be expected, GLP-1 stimulates relatively more insulin secretion than in our IGT group.

In strong contrast to the loss of the GLP-1 peak, the AIR seemed to be rather well preserved in our IGT group. This is consistent with previous data finding no difference whatsoever in insulin response to arginine in IGT subjects at fasting glucose concentrations [16]. Although at $14 \mathrm{mmol} / \mathrm{l}$ glucose, a significantly lower AIR was found in that study, the peak character was still well preserved. Taken together, those and our data suggest that the secretory insulin response to arginine itself is intact whereas the glucose-modulatory portion could be defective. Nevertheless, it is important to note that some subjects had a very low maximum ( $<5 \%$ of NGT) but an average first-phase secretion (e.g. $\bigcirc$ in Fig. 4).

In vitro data support the concept that the signalling pathways of GLP-1 compared with glucose to insulin secretion are independent at least upstream of calmodulin-dependent protein kinase (CaMK) [24]. In various insulin-secreting cells GLP-1 was shown to stimulate not only the voltage-dependent calcium channel but also the release of calcium from intracellular stores $[25,26]$ which "sets the stage" for glucosemediated insulin secretion. In this sense GLP-1 acts as a potentiator of glucose-induced insulin secretion as proposed previously [27]. It is thus conceivable that, for example, a defect in pathways specific for the GLP-1 signalling to the mobilisation of intracellular calcium stores contributes to the pathogenesis of the insulin secretion defect in IGT.

Less is known about the exact intracellular mechanism mediating the strong insulin secretagogue effect of arginine. Different modes of action have been proposed from both in vitro and in vivo studies: (1) stimulation of glucagon secretion, which induces insulin secretion by the glucagon receptor and cAMP-dependent pathways [26], (2) nitric oxide-mediated pathways $[15,28]$ and $(3)$ amino-acid transporter-dependent pathways [29]. In contrast to the GLP-1 peak the AIR in some of our IGT subjects approached or even exceeded the mean AIR of the NGT subjects
(Fig. 4). It is currently not clear why arginine-induced insulin secretion is preserved over a relatively long period of time during the development of beta-cell failure. Notably, in patients with "early" Type I (insulin-dependent) diabetes mellitus the insulin response to arginine was also best preserved [30].

Parenthetically, the infusion of GLP-1 restored insulin secretion in IGT to levels which exceeded those observed in NGT before the start of the GLP-1 infusion, i.e. during hyperglycaemia itself. Thus, our data strongly support the concept of GLP-1 as a therapeutic agent to improve the defective insulin secretion in patients with Type II diabetes [14, 31].

In this Caucasian cohort defective insulin secretion is critical for the development of IGT and presumably also Type II diabetes. The large interindividual variation in the pattern of impairment of the different phases of insulin secretion might reflect the heterogeneity of the mechanisms involved in betacell dysfunction. The first-phase insulin secretion and the acute secretory phase in response to GLP-1 were most impaired, whereas the acute response to arginine and the second phase of glucose-induced insulin secretion were least impaired. Because the peak in response to the start of the GLP-1 infusion was absent in IGT, it is possible that defects specifically in the incretin signalling pathway of the beta cell contribute to the pathogenesis of the insulin secretion defect of IGT and Type II diabetes.

Acknowledgements. We thank all the research volunteers for their participation. We gratefully acknowledge the excellent technical assistance of A. Teigeler, I. Riedlinger, E. Metzinger, U. Schmidt, S. Obermüller and S. Wolff. We are also indebted to S. Schützenauer, a medical student, who helped with many experiments. This study was supported by a research grant from the University of Tübingen (fortüne project No 1284100 ) and a grant from Novo Nordisk Mainz, to Drs. Fritsche and Stumvoll.

\section{References}

1. DeFronzo RA (1988) The triumvirate: B-cell, muscle, and liver: a collusion responsible for NIDDM. Diabetes 37: 667-687

2. Yki-Järvinen H (1992) Glucose toxicity. Endocr Rev 13: 415-431

3. Yki-Järvinen H (1995) Role of insulin resistance in the pathogenesis of NIDDM. Diabetologia 38: 1378-1388

4. Köbberling J, Tillil H (1982) Empirical risk figures for firstdegree relatives of non-insulin-dependent diabetics. In: Köbberling J, Tattersall R (eds) The genetics of diabetes mellitus. Academic Press, London pp 202-209

5. Heine RJ, Nijpels G, Mooy JM (1996) New data on the rate of progression of impaired glucose tolerance to NIDDM and predicting factors. Diabet Med 13: S12-S14

6. Lillioja S, Mott DM, Howard BV et al. (1988) Impaired glucose tolerance as a disorder of insulin action. Longitudinal and cross-sectional studies in Pima Indians. N Engl J Med 318: 1217-1225 
7. Eriksson J, Franssila-Kallunki A, Ekstand A et al. (1989) Early metabolic defects in persons at increased risk for non-insulin-dependent diabetes mellitus. N Engl J Med 321: 337-343

8. Kolterman OG, Gray RS, Griffin J et al. (1981) Receptor and postreceptor defects contribute to the insulin resistance in non-insulin-dependent diabetes mellitus. J Clin Invest 68: 957-969

9. Pimenta W, Mitrakou A, Jensen T, Yki-Järvinen H, Daily G, Gerich J (1996) Insulin secretion and insulin sensitivity in people with impaired glucose tolerance. Diabet Med 13: S33-S36

10. Byrne M, Sturis J, Sobel RJ, Polonsky KS (1996) Elevated plasma glucose $2 \mathrm{~h}$ postchallenge predicts defects in $\beta$-cell function. Am J Physiol 270: E572-E579

11. O'Rahilly SP, Rudenski A, Burnett MA et al. (1986) Betacell dysfunction rather than insulin insensitivity is the primary defect in familial type 2 diabetes. Lancet ii: 360-364

12. Ahren B, Larsson H, Holst JJ (1997) Reduced gastric inhibitory polypeptide but normal glucagon-like peptide 1 response to oral glucose in postmenopausal women with impaired glucose tolerance. Eur J Endocrinol 137: 127-131

13. Nauck MA, Heimesaat MM, Orskov C, Holst JJ, Ebert R, Creutzfeldt W (1993) Preserved incretin activity of glucagon-like peptide 1 [7-36 amide] but not of synthetic human gastric inhibitory polypeptide in patients with type- 2 diabetes mellitus. J Clin Invest 91: 301-307

14. Nauck MA, Sauerwald A, Ritzel R, Holst JJ, Schmiegel W (1998) Influence of glucagon-like peptide 1 on fasting glycemia in type 2 diabetic patients treated with insulin after sulfonylurea secondary failure. Diabetes Care 21: 1925-1931

15. Schmidt HH, Warner TD, Ishii K, Sheng H, Murad F (1992) Insulin secretion from pancreatic B cells caused by L-arginine- derived nitrogen oxides. Science 255: 721-723

16. Larsson H, Berglund G, Ahren B (1995) Glucose modulation of insulin and glucagon secretion is altered in impaired glucose tolerance. J Clin Endocrinol Metab 80: 1778-1782

17. Ward WK, Bolgiano DC, McKnight B, Halter JB, Porte D Jr (1984) Diminished B cell secretory capacity in patients with noninsulin-dependent diabetes mellitus. J Clin Invest 74: $1318-1328$

18. World Health Organization Expert Committee Second report on diabetes mellitus (1980) Technical report series No 646, WHO, Geneva

19. Pimenta W, Korytkowski M, Mitrakou A et al. (1995) Pancreatic beta-cell dysfunction as the primary genetic lesion in NIDDM. JAMA 273: 1855-1861
20. Orskov C, Wettergren A, Holst JJ (1993) Biological effects and metabolic rates of glucagonlike peptide-1 7-36 amide and glucagonlike peptide-1 7-37 in healthy subjects are indistinguishable. Diabetes 42: 658-661

21. Van Cauter E, Mestrez F, Sturis J, Polonsky KS (1992) Estimation of insulin secretion rates from C-peptide levels. Comparison of individual and standard kinetic parameters for C-peptide clearance. Diabetes 41: 368-377

22. Eaton RP, Allen RC, Schade DS, Erickson KM, Standefer J (1980) Prehepatic insulin production in man: kinetic analysis using peripheral connecting peptide behavior. J Clin Endocrinol Metab 51: 520-528

23. Nauck M, Stockmann F, Ebert R, Creutzfeldt W (1986) Reduced incretin effect in Type II (non-insulin-dependent) diabetes. Diabetologia 29: 46-52

24. Karlsson S, Fridolf T, Ahren B (1994) Islet mechanism of CCK-8 and GLP-1 (7-36) amide. In: Flatt P, Lenzen S (eds) Frontiers of insulin secretion and pancreatic b-cell research. Smith-Gordon Nishimura, Singapore pp 337-351

25. Holz GG, Leech CA, Heller RS, Castonguay M, Habener JF (1999) cAMP-dependent mobilization of intracellular $\mathrm{Ca} 2+$ stores by activation of ryanodine receptors in pancreatic beta-cells. A $\mathrm{Ca} 2+$ signaling system stimulated by the insulinotropic hormone glucagon-like peptide-1(7-37). J Biol Chem 274: 14147-14156

26. Gromada J, Bokvist K, Ding WG, Holst JJ, Nielsen JH, Rorsman P (1998) Glucagon-like peptide 1 (7-36) amide stimulates exocytosis in human pancreatic beta-cells by both proximal and distal regulatory steps in stimulus-secretion coupling. Diabetes 47: 57-65

27. Drucker DJ (1998) Glucagon-like peptides. Diabetes 47: 159-169

28. Spinas GA, Laffranchi R, Francoys I, David I, Richter C, Reinecke M (1998) The early phase of glucose-stimulated insulin secretion requires nitric oxide. Diabetologia 41: 292-299

29. Blachier F, Mourtada A, Sener A, Malaisse WJ (1989) Stimulus-secretion coupling of arginine-induced insulin release. Uptake of metabolized and nonmetabolized cationic amino acids by pancreatic islets. Endocrinology 124: 134-141

30. Ganda OP, Srikanta S, Brink SJ et al. (1984) Differential sensitivity to beta-cell secretagogues in "early" type I diabetes mellitus. Diabetes 33: 516-521

31. Rachman J, Barrow BA, Levy JC, Turner RC (1997) Nearnormalisation of diurnal glucose concentrations by continuous administration of glucagon-like peptide-1 (GLP-1) in subjects with NIDDM. Diabetologia 40: 205-211 